\title{
PRÁTICAS EDUCATIVAS E ESCOLARES NA ROMA ANTIGA
}

\author{
Elisa Figueira de Souza Corrêa* \\ (Universidade do Estado do Rio de Janeiro)
}

\begin{abstract}
RESUMO: este texto faz um recorte na história da educação durante a antiga civilização romana, considerando-se especialmente a influência da cultura e educação grega através de dois de seus primeiros educadores, Lívio Andrônico e Quinto Ênio, e da literatura grega clássica.
\end{abstract}

Palavras-Chave: história da educação; Roma Antiga; Lívio Andrônico; Quinto Ênio; literatura grega clássica.

\section{EDUCATIONAL AND SCHOOL PRACTICES IN ANCIENT ROME}

ABSTRACT: this text resumes part of the history of education during ancient Roman civilization, focusing on the influences of ancient Greek culture and education through two of its first educators, Livius Andronicus and Quintus Ennius, and classic Greek literature.

KEYWORDS: history of education; Ancient Rome; Livius Andronicus; Ennius; classic Greek literature.

\section{Introdução}

Ao se conhecer um pouco mais sobre a própria história da educação escolar na Antiguidade Greco-Romana, pode-se perceber sua influência presente ainda hoje em nossas salas de aula. Embora este texto não faça mais que um breve resumo histórico - em verdade, praticamente um fichamento comentado - sobre a estrutura formal e algumas práticas escolares no berço da civilização ocidental, creio que poderá ser útil àqueles que, desconhecendo as fontes aqui citadas, porventura se interessem pelo assunto.

Por experiência própria, tenho certeza de que a muitos surpreenderá saber há quantos séculos o formato da instituição escolar permanece praticamente imutável.

Em especial, com este texto, queremos fazer notar a grande influência que a educação grega terá sobre a cultura romana. Esse fato tão conhecido poderá ser mais bem explicado ao observarmos como, na verdade, o modelo de educação grega (cf. SOUZA CORRÊA, 2018) já era anterior à própria Grécia (mas

\footnotetext{
*E-mail: elisa.correa@uerj.br
} 
aperfeiçoado e sedimentado nesta) e como esse modelo se transmitiu aos romanos e seu grande império.

Para uma compreensão completa para a formação da nossa própria escola, portanto, é preciso seguir na leitura sobre o projeto e o estabelecimento da escola na Antiga Roma.

\section{Primórdios da educação romana}

Marrou (1971, p. 358) nos ensina que, pelos fins do séc. IV, Roma e sua cultura eram dominadas por uma aristocracia campesina, i.e., proprietários rurais explorando diretamente suas terras e, portanto, formando uma classe bastante diferente daquela que deu origem à cultura e ao projeto pedagógico grego. A evolução dos fatos, contudo, há de fazer com que a educação grega termine por ter grande influência e, opinam alguns, seja o modelo-base da educação romana ainda que esta conserve alguns de seus traços originais.

Os primeiros registros de literatura latina existentes hoje e também o próprio marco inicial desta literatura advém das traduções de clássicos gregos. Andrés Pociña (1998, p. 14) advoga que antes disso a produção artística em Roma devia resumir-se a composições de três tipos. Os dois primeiros seriam os carmina conuiualia, isto é, poemas cantados com acompanhamento de flauta em banquetes, em exaltação a homens ilustres, e os neniae, ou seja, lamentos cadenciados, executados durante funerais por mulheres assalariadas, cantando as virtudes do defunto. Infelizmente não há vestígios nem dos primeiros nem dos últimos e o pouco que se sabe deles deve-se a fontes indiretas, como obras de Cícero e outros autores posteriores.

Um terceiro tipo de composição seriam os scipionum elogia. A relevância desse gênero encontra-se no fato de que, segundo Pociña (1998, p. 14), especialmente graças aos elogios é que se teriam preparado os ânimos para a constituição de uma épica latina, uma vez que seu tema e sua métrica se aproximavam da literatura grega e a época de composição desses elogios são coincidentes com a das primeiras composições a chegarem a Roma. Assim, Pociña (1998, p. 14) afirma:

los elogia, junto com las neniae y los carmina conuiualia, estos dos com probables inquietudes poéticas, aquéllos com evidente sentido artístico, favorecieron que la épica griega no resultase extraña en absoluto al pueblo latino, que de este modo la adoptó y la hizo suya sin gran dificuldad.

Não é possível tampouco desprezar o contexto histórico que favoreceu o início da literatura latina. O século III a.C. foi marcado pela crescente expansão do Império Romano. Entre 281-272 a.C., foi travada a guerra contra a cidade de Pirro e, em seguida, a primeira Guerra Púnica (264-241 a.C.), o que colocara Roma e Grécia em prolongado contato direto.

Para celebrar o fim da guerra contra Cartago, então, em 240 a.C. ocorre a primeira representação teatral pública na urbe romana - uma peça nos moldes gregos. Tal fato tampouco deve ser estranhado, pois, nesse tocante, é bom lembrar que a cultura romana sempre foi descrita por seus estudiosos como muito prática e aberta a receber o novo, uma característica que já tinha sido ressaltada pelos próprios pensadores antigos. Assim, o historiador e geógrafo grego Políbio (203120 a.C.) já escrevia em suas Histórias (VI-25, 11), ainda que com tom crítico, que os romanos mais que qualquer outro povo, troca facilmente seus costumes e 
imita o que é melhor que o seu (apud POCIÑA, 1998, p. 13). Tal crítica foi, contudo, sabiamente rechaçada já pelos próprios romanos. Como comenta Pociña (1998, p. 13), esse era um comportamento totalmente plausível, de nenhuma forma merecedor dessa crítica fácil a que com frequência se lhes há submetido. $\mathrm{O}$ poeta Caio Salústio Crispo (86-34 a.C.), por exemplo, em seus escritos sobre a conjuração de Catalina no senado romano (Cat. 51, 37-38), comentou esse hábito romano de modo mais positivo:

\begin{abstract}
Our ancestors, Fathers of the Senate, were never lacking either in wisdom or courage, and yet pride did not keep them from adopting foreign institutions, provided they were honourable. They took their offensive and defensive weapons from the Samnites, the badges of their magistrates for the most part from the Etruscans. In fine, whatever they found suitable among allies or foes, they put in practice at home with the greatest enthusiasm, preferring to imitate rather than envy the successful. (SALLUST, 1931. Grifos meus).
\end{abstract}

Tendo os romanos entrado em contato com a farta e rica literatura grega ao longo das décadas de batalhas que se estenderam nos primeiros momentos de expansão do Império Romano, não tardou, pois, para que começassem também a praticar e enriquecer com os exemplos helênicos sua própria literatura.

\title{
2.1 Lúcio Lívio Andrônico
}

$\mathrm{Na}$ verdade, aquele que é costumeiramente tido como o primeiro poeta romano era, de fato, um grego, um ex-escravo provavelmente pertencente à família Lívia (da qual herdou seu prenome latino após ser liberto): Lúcio Lívio Andrônico ${ }^{1}$. Pouco se sabe sobre sua vida e obra, e mesmo sua data de nascimento e morte podem apenas ser especuladas, entre, aproximadamente, 284 e 204 a.C. Também a data precisa de sua chegada a Roma é incerta, sendo que alguns acreditam ter sido 272 a.C. e outros 249 a.C.

Conquanto Pociña (1998) lembre que já havia tradição poética em Roma anteriormente, é de Lívio Andrônico o primeiro drama escrito em latim e encenado em 240 a.C. para as comemorações do fim da I Guerra Púnica. Os relatos que chegaram a nós falam de um poeta de qualidade duvidosa. Cícero considera sua obra antiquada e pouco interessante, por exemplo (DICIONÁRIO OXFORD, 1987, p. 309), mas Andrônico parece ter tido bastante êxito com suas comédias e tragédias, geralmente de tema homérico-mitológicos. Tanto é assim que, segundo Pompeu Festo (apud POCIÑA, 1998, p. 27), o Estado dedicou-lhe honrarias por um partênio ${ }^{2}$ seu, dando-lhe espaço no templo de Minerva, em Aventino, para criar um centro de reunião de escritores e atores (collegium poetarum), e dando a Lívio Andrônico o cargo de presidente do grupo. Note-se que, além de escrever, Andrônico também atuava em suas peças, como era o costume então.

Além de escrever comédias e dramas, também se sabe que a Lívio Andrônico foi encomendado o hino que lhe rendeu honrarias e do qual também não sobrou vestígio. Mais nos interessa, contudo, o feito pelo qual seu nome ficaria mais famoso até os dias de hoje: é de Andrônico a primeira versão para o

\footnotetext{
${ }^{1}$ Em latim, Lucius Livius Andronicus. Andrônico marcaria sua origem grega (androníkos).

${ }^{2}$ Hino patriótico cantado e dançado em cerimonial religioso.
} 
latim da Odisseia, de Homero, à qual deu o nome latino de Odusia. Note-se ainda que o motivo que aparentemente o fez levar a cabo tal feito foi para utilizar o texto em suas aulas, uma vez que Lívio Andrônico também era professor tanto de latim como de grego.

A importância histórica de Lívio como um inovador é considerável. Ele representa o primeiro impacto da Grécia sobre Roma, pois introduziu na literatura romana a poesia épica, o drama e a poesia lírica. Sua tradução da Odisseia continuou a ser um livro escolar até a época de Augusto, e Horácio nos diz que era costume aprendê-la de cor sob a ameaça da palmatória de [seu professor] Orbílio. (DICIONÁRIO OXFORD, 1987, p. 309).

Dessa forma, entende-se que, como poeta, Andrônico viveu compondo obras dramáticas para a cena latina, mas, como professor, também viveu lendo e interpretando não só seus próprios versos como obras literárias gregas para seus discípulos e para os "romanos incultos", segundo Suetônio (apud BIGNONE, 1952, p. 34).

\footnotetext{
En Roma es muy posible que fuese esclavo de um membro de la família Livia, según Jerónimo, de um Livio Salinator, de cuyos hijos fue preceptor, y que posteriormente le concedió la libertad y, con ello, el nombre. Además, es también perfectamente creíble el dato de Suetonio (Gramm. 1) que lo coloca com Enio entre los poetas antiquísimos que, siendo semigriegos, se dedicaban a la enseñanza en ambas lenguas. (POCIÑA, 1998, p. 15).
}

Enzo Marmorale (1974, p. 47) nota que Lívio Salinátor não era um cidadão qualquer, mas um senador, donde se pode perceber algo do valor, na época, de um escravo como Andrônico e da educação em Roma. "Por necessidades políticas e comerciais, se tornava necessário para os Romanos o estudo da língua grega", afirma Marmorale, acrescentando ainda que Lívio Andrônico teria aberto uma escola à qual acorreram os jovens das melhores famílias, tendo vivido amado e estimado entre as preocupações do ensino e a versão de textos gregos que pudessem servir de leitura aos jovens da escola (MARMORALE, 1974, p. 47).

Por essa razão teria traduzido a Odisseia e, ao fazê-lo, adotou os versos saturnianos (ou satúrnios), tradicionais à época (embora dissonantes com a métrica grega), dando à obra um sabor romano. Talvez por isso também sua tradução tenha se tornado rapidamente malvista, enquanto sua obra dramática nem tanto, uma vez que esta Andrônico traduziu livremente. Para Bignone (1952, p. 34), uma dificuldade proveio certamente da natureza distinta, e muito inferior, do saturnianos, frente ao maravilhoso instrumento de arte que era o hexâmetro de Homero, tão musical em cada uma de suas fibras.

Na verdade, segundo Marmorale (1974, p. 48), a tradução da epopéia grega não teria sido feita tanto para seus alunos quanto para os romanos em geral. A saga de Ulisses, mais do que a Ilíada, permitia uma identificação com o espírito romano e os versos saturnianos ajudava tanto mais. O fato de ser uma tradução descuidada, "imperfeita", poderia ser atribuído ao fato de que seus alunos mesmos, de famílias nobres, poderiam ler o original depois de seus ensinamentos, diferente da maior parte do povo, para quem a língua grega era desconhecida. Outra questão é o fato de a literatura e o gosto literário romanos estarem naquela época ainda 
embrionárias. O próprio Marmorale retruca mais adiante em seu texto as críticas de Cícero e de Tito Lívio ao grego:

O juízo que dele [o hino para Juno] nos deixaram os antigos é muito severo. [...] Nem diferente foi o juízo formulado acerca das outras obras suas: Cícero de facto (Brutus 18, 71) compara a Odisseia de Lívio a uma obra rude e imperfeita de Dédalo (Odissyia Latina est sic tamquam opus aliquod Daedali) e [considera] as suas tragédias e comédias não dignas de serem relidas [...]. Mas Tito Lívio e Cícero julgam com o gosto apurado da sua época, esquecendo que o juízo sobre obras que, por serem as primeiras na sua língua, não podem ser perfeitas, é muito diferente daquele que se deve formular de obras aparecidas em tempo de maturidade. (MARMORALE, 1974, p. 48).

Sendo assim, vemos que nos primórdios da educação romana, a tradução tinha um papel de instrumento didático crucial. Além disso, a literatura, tendo sido escolhida (como o foi na Grécia), como meio primário para a educação dos jovens florescerá junto com a escola.

\subsection{Quinto Ênio (239-169 a.C.)}

O outro poeta do período arcaico de Roma e que nos é de interesse é Quinto $\hat{E}{ }^{3}{ }^{3}$, considerado pelos romanos como o pai da poesia latina, poeta de vasta obra, apreciado em seu tempo e depois. Nasceu em Rúdias, na Calábria, uma região na época parcialmente osca e parcialmente grega que, mais tarde, viria a ser assimilada ao Império Romano. Daí que Ênio se tornasse proficiente nas três línguas, donde sua célebre frase afirmando que tinha "três corações": um grego, um latino e um osco ${ }^{4}$.

Ênio serviu no exército, mas, ao deixá-lo, foi morar numa humilde casa no Aventino, onde viveu escrevendo e lecionando. Em 184 a.C., ao voltar de mais uma temporada nos campos de batalha, obteve um terreno para cultivar no território piceno e recebeu também a cidadania romana, como recompensa por ter educado muitos jovens e cantado num poema épico a glória de Roma (MARMORALE, 1974, p. 63). De fato, segundo o Dicionário Oxford (1987, p. 192), sua obra teve grande importância por sua influência civilizadora e humanizante, expondo os problemas da vida em diálogos vigorosos e poéticos.

Vários dos grandes nomes de Letras da antiga Roma que se seguiram fazem referência a Ênio, dando prova do quão importante e influente foi deveras sua obra. Alguns, como Lucrécio, Virgílio e Ovídio imitaram-no e é graças à admiração e diversas citações feitas por Cícero que muito da obra de Ênio chegou até nossos dias. O poeta gozou, então, de longo período de estima entre os críticos romanos de épocas posteriores e mesmo as críticas que lhe faz Horácio são vistas hoje como menores, uma vez que o próprio Horácio o chama de "pai da poesia latina" e recorre ao poeta por vezes.

Marmorale (1974, p. 65) afirma que o maior poema de Ênio, os Anais, entrou muito cedo nas escolas: "começou a ser lido em público e comentado já antes de Cícero. Este mesmo cita muitíssimos trechos dos Annales e chama a Énio sumo poeta épico". Foi também com os Anais que "os meninos das escolas

\footnotetext{
${ }^{3}$ Quintus Ennius em latim.

${ }^{4}$ Quem conta isso é Aulus Gellius (2014): "QUINTUS ENNIUS used to say that he had three hearts, because he knew how to speak Greek, Oscan, and Latin.” (QUINTUS ENNIUS tria corda habere sese dicebat, quod loqui Graece et Osce et Latine sciret).
} 
romanas tomaram conhecimento dos heróis antigos" (DICIONÁRIO OXFORD, 1987, p. 192). Embora tenham sobrado hoje apenas pouco mais de seiscentos do seus (prováveis) 15 mil versos, sabe-se que esse longo poema em vários volumes contava a história de Roma desde a vinda de Enéias, fugido de Tróia. É, então, um poema impregnado de fé patriótica e de tom grandiloquente. Bignone (1952, p. 51) chega a dizer que, com esse poema, Ênio se atreveu ao que nem mesmo os poetas gregos ousaram: um poema em que o herói não era um grande guerreiro mitológico, mas um povo inteiro, isto é, Roma. Seu sucesso, portanto, não foi à toa e "Gélio (XVIII 5, 2) faz-nos saber que os Annales, nos seus tempos, se liam no teatro, entre grandes aclamações" (MARMORALE, 1974, p. 66).

Se puede decir que pocos años antes de él [os Anais], Roma no tenía historia: único monumento recordatorio de sus héroes era la tumba. En su tempo la historia de Roma hacía ensayos inseguros y tímidos en la prosa griega de los primeros analistas; con Enio la historia se vuelve, aun en la forma, plenamente romana; sale de los anales polvorientos y entra en la espléndida luz de la poesía: la crónica analítica se hace epopeya de pueblo y drama de héroes. (BIGNONE, 1952, p. 51).

Por outro lado, Quinto Ênio, como Lívio Andrômaco, também se dedicou às tragédias $\mathrm{e}$ - novamente como o grego - especialmente às de temática troiana, sendo que Ênio aproximava-se mais de Eurípides. Ainda assim, há que se abstrair a grande liberdade com que se move Ênio com relação a seus modelos gregos, segundo se observa em comparação com aqueles, de modo que, por exemplo, em Medeia evitava grande número de nomes geográficos gregos, que careciam de importância a seus espectadores (POCIÑA, 1998, p. 54). A mesma liberdade tomava em relação à métrica, às vezes mantendo a original, às vezes a alterando, tendo sido o primeiro poeta latino a usar hexâmetros épicos à moda grega.

Além disso, da vasta obra conhecida de Ênio, cabe notar algumas de caráter nomeadamente didático (POCIÑA, p. 20): (a) as Saturae, poemas de miscelâneas, nos quais surgiam temas didáticos, enredos de fábulas, humorísticos etc. e que contavam com ao menos quatro livros. Além disso, (b) oito brevíssimos fragmentos se conservam de Epicharmus, um poema didático, escrito em septenários trocaicos. Alguns autores afirma que essa obra tratava da origem (física ou natural) do universo e das coisas. Por fim, (c) onze hexâmetros restam do poema didático, de tema gastronômico em tom satírico, Hedyphagetica, que seguia o modelo do também siciliano Arquéstrato de Gela em sua obra O livro dos gulosos ou da boa mesa (BIGNONE, 1952, p. 51). Bignone (1952, p. 51) cita ainda outras obras de caráter "filosófico-reflexivo" de Ênio: (d) Euhemerus, na qual reproduzia doutrinas de Euémero sobre os deuses, originariamente humanos que foram divinizados pela admiração que provocaram; e (e) Protrepticus, um livro de iniciação à filosofia.

Não é coincidência que Ênio fosse considerado um grande educador em Roma. De fato, além desse uso didático da poesia, havia ainda suas "atividades gramaticais". A ele é atribuída ainda

a reforma da língua latina, a subordinação da mesma língua a uma mais segura e precisa norma quantitativa e o travão posto à decadência morfológica, pela qual a língua latina tendia a simplificar-se, perdendo a flexão dos casos e a conjugação simples dos verbos. Em substância, Ênio retardou aquela transformação do latim, que devia [sic] verificarse depois, quando do latim dimanaram as línguas românicas. (MARMORALE, 1974, p. 69). 
3. A educação escolar romana

Embora, primitivamente, a educação em Roma fosse muito limitada, restringindo-se quase que tão-somente a saber as leis e a exercícios físicos, a partir do influxo de cultura grega isso muda bastante. Assim, se inicialmente relata-se que Catão, o velho, educara a seu próprio filho, entre os séculos IV e III a.C. começam os registros da existência de escolas ou de indivíduos encarregados da educação das crianças.

\begin{abstract}
Em decorrência do contato com a cultura helenística, a educação passou a ser confiada a um preceptor ou a uma escola; os professores eram frequentemente escravos ou libertos, muitas vezes gregos, e os discípulos aprendiam, entre outras coisas, sententiae ou máximas morais, além da leitura, escrita e cálculo. (DICIONÁRIO OXFORD, 1987, p. 181).
\end{abstract}

E como muitos dos escravos não eram romanos, e sim gregos ou de povos de outras terras assimiladas pelo Império, devemos nos perguntar sobre como esses professores estrangeiros ensinavam as crianças romanas. No entanto, como visto anteriormente, os professores mais cobiçados eram certamente os gregos, graças ao valor dado a essa cultura em Roma. O status superior que a cultura e a língua gregas possuíam para Roma, uma vez que, como bem notou Selma Martins-Cestaro (1999), os romanos não fizeram o mesmo esforço em relação a nenhum dos outros povos, "bárbaros", conquistados, é fato comprovável pela diminuta influência que estes tiveram sobre a cultura latina geral se comparado ao substrato grego. Além disso, o grego continuou a ser a língua oficial da porção oriental do Império Romano, cuja sobrevida foi mil anos maior que a da porção ocidental.

Além disso, o Dicionário Oxford (1987, p. 181) também anota que

\footnotetext{
uma figura característica, introduzida graças à influência grega, era o paedagogus, um escravo que acompanhava a criança à escola, permanecia à sua espera lá e a trazia de volta à casa; ele ensinava o menino a falar grego e cuidava de suas maneiras e de sua moral.
}

Além disso, "havia também em Roma a escola mais graduada do grammaticus, onde o ensino era de natureza mais literária, em latim e grego, sobre linguagem, gramática, métrica, estilo e o conteúdo de poemas" (DICIONÁRIO OXFORD, 1987, p. 181).

Toda essa educação em grego rendeu frutos sobre a vida e cultura romanas. Bignone (1952, p. 14) observa que em 282 Lúcio Postumio, embaixador romano em Tarento, expressava-se em grego em ocasiões oficiais, ainda que com erros, e mesmo os primeiros historiadores romanos também escreviam em grego. Entre as palavras latinas de caráter técnico, ou relativas à vida de luxo, ou às artes muitas são as de origem grega. E, como já visto, da Magna Grécia e da Campanha serão os primeiros poetas romanos: Lívio Andrônico, Quinto Ênio e ainda Névio. Mesmo nos autores romanos a presença estrangeira se faz notar, como nas peças de Plauto, nas quais os escravos empregam helenismos com maior frequência, indicando sua origem.

Além disso, após ganhar a toga virilis, ou seja, a partir do momento em que passava a ser um cidadão, um jovem romano podia ir estudar filosofia em Atenas ou Rodes ou algum outro centro educacional grego. Alguns grandes nomes latinos estudaram no exterior (e.g. César, Cícero, Otaviano e Horácio) e os efeitos 
da educação retórica grega podem ser sentidos na literatura romana tardia (DICIONÁRIO OXFORD, 1987, p. 182).

$\mathrm{O}$ fato desse intercâmbio cultural ter sido tão profícuo nos faz crer na existência de uma "didática", ainda que em desenvolvimento, no ensinoaprendizagem de língua não-materna na época do Império Romano. No entanto, conquanto se saiba que Andrônico e Ênio eram professores de grego - assim como tantos outros escravos e estrangeiros anônimos -, pouco se sabe sobre seus métodos de ensino.

O mais provável é que utilizassem exercícios de tradução como técnica de ensino, pois um dos primeiros exemplos de uso pedagógico da tradução, embora sem relação explícita com o ensino de língua não-materna, encontra-se também na Roma Antiga, onde os exercícios conhecidos como imitatio eram utilizados pelos estudantes de oratória e de retórica para aperfeiçoarem seu estilo no século I a.C.

pedagogically, it [imitatio] was used for revision exercises, in which students were taught to write or orate by rewriting or respeaking classic texts - changing them in some significant way, choosing new words for saying the same thing. (ROBINSON, 2001, p. 111).

A princípio, esses textos clássicos costumavam ser textos latinos os quais seriam, portanto, apenas parafraseados, mas é explicando tais exercícios que o grande orador romano, Marco Túlio Cícero (106 a.C.-43 d.C.), defende explicitamente que os textos escolhidos fossem preferencialmente gregos, como se lê na citação a seguir. Ou seja, transforma os imitatio em exercícios de tradução para fins de aprendizado estilístico e de enriquecimento linguístico.

Mais uma vez, então, vemos como os primórdios da escola está ligada à presença da literatura nas salas de aula, tanto como exemplo modelar de caráter etc. a ser seguido pelos jovens, como no exemplo de língua (gramática e retórica) a ser copiado.

Infelizmente, sabemos também como esse uso de textos literários em Roma irá se degradar e se reduzir à análise de sintagmas cada vez menores, tornando-se meros instrumentos para a análise sintática ou morfossintática.

A escola, após Roma, seguirá um longo e, por vezes, tortuoso caminho até chegar aos nossos dias, de tentativa do resgate do sabor da leitura e da revisão do lugar da gramática no Ensino Fundamental. Por isso, neste momento, de que muito vale observar e aprender com seus primórdios, para compreensão de suas origens e retomada do que já houve de interessante, ainda que com novas facetas.

\section{Referências}

BIGNONE, Ettore. Historia de la literatura latina. Tradução Gregorio Halperín. Buenos Aires: Losada, 1952.

DICIONÁRIO OXFORD de literatura clássica: grega e latina. Paul Harvey. Tradução Mário da Gama Kury. Rio de Janeiro: Jorge Zahar, 1987. 
MARMORALE, Enzo V. História da literatura latina. Tradução João Bartolomeu Jr. Lisboa: Estúdios Cor, 1974. (Histórias das grandes literaturas, 3). ABL

MARROU, Henri-Irénée. História da educação na antiguidade. São Paulo: Herder; USP, 1971.

POCIÑA, Andrés. Épica y teatro: la primera poesía. Desde sus comienzos hasta el siglo I a.C. In: CODONER, Carmen. (ed.). Historia de la literatura latina. Madrid: Catedra, 1998? p. 13-70.

ROBINSON, Douglas. Imitation. In: BAKER, Mona (org.). Routledge encyclopedia of translation studies. Londres; Nova Iorque: Routledge, 2001. p. 111-2. 